\title{
SUSPENDED SEDIMENT CONCENTRATION DISTRIBUTION IN AN ALLUVIAL CHANNEL FLOW
}

\author{
DANG HUU CHUNG \\ Institute of Mechanics, NCNST of Vietnam
}

\begin{abstract}
SUMMARY. In this paper a numerical solution for the problem on suspended sediment concentration distribution in an alluvial channel flow has been computed on the base of PROFILE model proposed by L. C. Van Rijn for the case of uniform flow. Although, in the present case, mathematical model is quite simple, but it is exact enough to apply to somme problems in practice. The aim of the paper is that the author would like to use the finite difference method for the same problem. The input data was used from experiment fume. The result showed that the concentration distribution fast decreased along the channel and concentration gradients became very small at the sections situated far enough from the upstream. Besides, a computing programme with the ability of graphic expression was established.
\end{abstract}

\section{§1. INTRODUCTION}

The computation of vertical distribution of suspended sediment in a flow is one of the problems relating to sedimentation and morphological processes. It really plays important role in many problems in practice, specially, in dealing with the deposit at estuaries as well as the management of the quality water. Nowadays, it is interesting many scientists in the world. The mathematical model consists of hydrodynamics equations for velocity field and the sediment diffusion-convection equation. The overview of this we can find in many papers (such as [3]). In this paper, however, only a special case of steady uniform flow was studied. In point of view of economics it is fully reasonable to study such a problem. In fact, the errors in input data measurement are too big, according to L. C. Van Rijn it's about 25\% [4]. Therefore in some cases we can consider the problem with a simpler model.

In the following the implicit finite difference method will be applied to compute the vertical distribution of suspended sediment concentration in a steady uniform flow. The input data is used from experiment flume by Wang an Ribberink [5]:

\section{§2. BASIC EQUATIONS AND BOUNDARY CONDITIONS [6]}

The equation of motion for a steady uniform flow is relatively simple and is represented by a resistance formula. Here we should repeat its formation briefly. From the equilibrium of forces in $x$-direction along the channel axis it follows that

$$
\tau_{z}=\rho g S(h-z)
$$

where $\tau_{z}$ is the shear stress, $h$ the water depth, $\rho$ the water density, $z$ the distance from the bed, $g$ the acceleration of gravity, $S$ the bed slope 
From Reynolds' equations the shear stress at height $z$ in steady uniform flow can be represent. as follows

$$
\tau_{z}=\rho \nu \frac{d u}{d z}-\rho \overline{u^{\prime} w^{\prime}}
$$

where $\nu$ is kinematic viscosity, $u^{\prime}, w^{\prime}$ velocity fluctuations

Using equations (2.1) and (2.2) and neglecting the viscous shear stress in the sublayer gi' the following relation when $z=0$

$$
-\overline{u^{\prime} w^{\prime}}=\frac{\tau_{b}}{\rho}
$$

By definition of $\tau_{b}$ and using the mixing length concept proposed by Prandtl in equation (2.: they obtain the equation

$$
\frac{d u}{d z}=\frac{u_{*}}{k z}
$$

in which $u_{*}$ is the bed shear velocity, $k$ the constant of Von Karman

Integrating equation (2.4) and using Chezy-formula give the velocity distribution over the fu depth for smoot and rough flows

$$
u=\frac{g^{0.5}}{k C} \operatorname{Ln}\left(z / z_{0}\right) \vec{u}
$$

in which $\bar{u}$ is the cross-section averaged velocity, $z_{0}$ zero-velocity level and $C$ Chezy coefficien They are determined by the formulae

$$
\begin{gathered}
z_{0}=0.033 k_{s} \\
C=18 \log \left(\frac{12 h}{k_{s}}\right)
\end{gathered}
$$

where $k_{*}$ is the effective bottom roughness

For the steady state condition, small longitudinal diffusion terms and constant settling velocit: , the sediment diffusion-convection equation has the simple form as follows

$$
u \frac{\partial c}{\partial x}-w_{s} \frac{\partial c}{\partial z}-\frac{\grave{\partial}}{\partial z}\left(\varepsilon, \frac{\partial c}{\partial z}\right)=0
$$

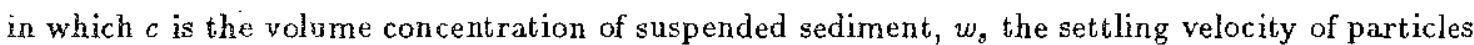
$\varepsilon_{s}$ sediment mixing coefficient

We also can find this case in the other works, such as Hjelmfelt and Lenau [1], and Jobson and Sayre [2]. However, the mixing coefficient $\varepsilon_{y}$ and the boundary condition at the bed were used from the other formulae. Up to now there are many different formulae to determine them. In the present paper we use the parabolic-constant sediment mixing coefficient through that for fluid, $\varepsilon_{f}$; proposed by Coleman and Kerssens [5] as follows

$$
\varepsilon_{9}=\beta \phi \varepsilon_{f}
$$

in which

$$
\varepsilon_{f}= \begin{cases}\varepsilon_{f \max }-\varepsilon_{f \max }\left(1-\frac{2 z}{h}\right)^{2}, & \text { for } \frac{z}{h}<0.5 \\ \varepsilon_{f \max }=0.25 k u_{*} h, . & \text { for } \frac{z}{h} \geq 0.5\end{cases}
$$

$\beta$-proportional factor and $\phi$ turbulence damping factor

In the case of equilibrium concentration profile, we easily obtain from equation $(2.6)$

$$
c_{e}=c_{a e} \exp \left(-\int_{a}^{z} \frac{w_{s}}{\varepsilon_{y}} d z\right)
$$


in which $c_{a e}$ is the equilibrium concentration at the reference level, the subscript " $e$ " denotes the equilibrium flow

Integrating equation (2.8) with the assumption of small sediment concentration $(\phi=1)$ gives the equilibrium concentration distribution as follows :

$$
\frac{c_{e}}{c_{a e}}= \begin{cases}\left(\frac{a}{z} \cdot \frac{h-z}{h-a}\right)^{z}, & \text { for } \frac{z}{h}<0.5 \\ \left(\frac{a}{h-a}\right)^{z} \cdot \exp \left(-4 Z\left(\frac{z}{h}-0.5\right)\right), & \text { for } \frac{z}{h} \geq 0.5\end{cases}
$$

in which $Z=w_{s} /\left(\beta k u_{*}\right)=$ suspension parameter

In order that the problem is solved completely, the value of $c_{a e}$ is required. According to experiment formula proposed by Van Rijn [5]

$$
c_{a e}=0.015 \frac{d_{50}}{a} \frac{T^{1.5}}{D_{*}^{Q .3}}
$$

with

$$
\begin{aligned}
D_{*} & =d_{50}\left(\Delta g / \nu^{2}\right)^{1 / 3}, \quad \Delta=\frac{\rho_{s}-\rho}{\rho} \\
T & =\frac{\left(u_{*}^{\prime}\right)^{2}-\left(u_{*, c r}\right)^{2}}{\left(u_{*, c r}\right)^{2}} \\
u_{*}^{\prime} & =\frac{g^{0.5} \hat{u}}{C^{\prime}}, \quad C^{\prime}=18 \log \frac{4 h}{d_{90}}
\end{aligned}
$$

where $D_{*}$ is the dimensionless diameter of particle, $\Delta$ the relative density, $\rho_{s}$ the density of sediment, $u^{\prime}$ the effective bed shear velocity related to the grains, $u_{*, c r}$ the critical bed shear velocity according to Shields [7], $d_{50}$ and $d_{90}$ particle diameters of bed material;and $\nu$ the kinematic viscoscity coefficient

Here we'll use the following boundary conditions for sediment diffusion-convection equation

At the inflow boundary:

The equilibrium concentration, $c_{e}$, may be used as an the inflow boundary condition but in order to get higher accuracy, data from measurements is often suggested

$$
\left.c(x, z)\right|_{x=0}=f(z)
$$

where $f(z)$ is the given function of sediment concentration

At the bed boundary:

$$
\left.\varepsilon_{s} \frac{\partial c}{\partial z}\right|_{z=a}=0
$$

it means that the upward sediment flux doesn' $t$ occur.

At surface boundary:

$$
w_{s} c+\varepsilon_{s} \frac{\partial c}{\partial z}=0
$$

Besides, in order to compute in the concrete case the hydraulics conditions are necessary.

\section{§3. CONCRETE APPLICATION}

The implicit finite difference method has been used for the suspended sediment flow in an experiment flume carried out by Wang and Ribberink. The input data is as follows [5] 


\section{Hydraulic condition}

The flume was divided into three sections, an inflow section with a rigid bottom, a test sectio with a bottom made up of perforated plates and an outflow section with a rigid bottom. The tes section had a bottom slope of 0.001 . The discharge was $0.061 \mathrm{~m}^{3} / \mathrm{s}$. The water depth was $0.215 \mathrm{n}$ Due to sediment particles of different sizes, therefore the characteristic diameter and fall velocit of particles are $d_{50}=95 \mu \mathrm{m}$ and $w_{s, 50}$, respectively.

Boundary conditions and input data

The boundary conditions (2.11), (2.12) and (2.13) were used. The input data is:

\author{
mean current velocity \\ width \\ effective bottom roughness \\ ratio of sediment and fluid mixing coefficient \\ fluid density \\ sediment density \\ Constant of Von Karman \\ reference level \\ characteristic diameters \\ characteristic fall velocity
}

$$
\begin{aligned}
& \bar{u}=0.56 \mathrm{~m} / \mathrm{s} \\
& b=0.5 \mathrm{~m} \\
& k_{s}=0.0025 \mathrm{~m} \\
& \beta=1 \\
& \rho=1000 \mathrm{~kg} / \mathrm{m}^{3} \\
& \rho_{s}=2650 \mathrm{~kg} / \mathrm{m}^{3} \\
& k=0.4 \\
& a=0.00215 \mathrm{~m} \\
& d_{50}=95 \mu \mathrm{m} \\
& d_{90}=105 \mu \mathrm{m} \\
& w_{s, 50}=0.0065 \mathrm{~m} / \mathrm{s}
\end{aligned}
$$

\section{§4. RESULT OF COMPUTATION AND DISCUSSION}

The domain of computation was divided into 200 sections along $x$ axis with longitudinal grid size $d x=0.1 \mathrm{~m}$ and vertical grid consists of 30 points. The results showed that bed concentration fast decreased along the channel axis and the curve representing concentration distribution became more sloping towards the downstream, and this completely agrees with physical sense. The depth averaged concentration decreased from 0.14039 at $x=0$ down 0.0026 at $x=20 \mathrm{~m}$ and fully vanished at $x=24 \mathrm{~m}$. The figures from Fig. 1 to Fig. 4 showed suspended sedinment concentration distributions at positions $x=1 \mathrm{~m}, x=2 \mathrm{~m}, x=4.5 \mathrm{~m}$ and $x=8 \mathrm{~m}$, respectively.

Acknowledgement. This publication is completed with financial support from the National Basic Research Program in Natural Sciences. The author would like to thank Prof. Dr. Nguyen Van Diep for useful remarks.

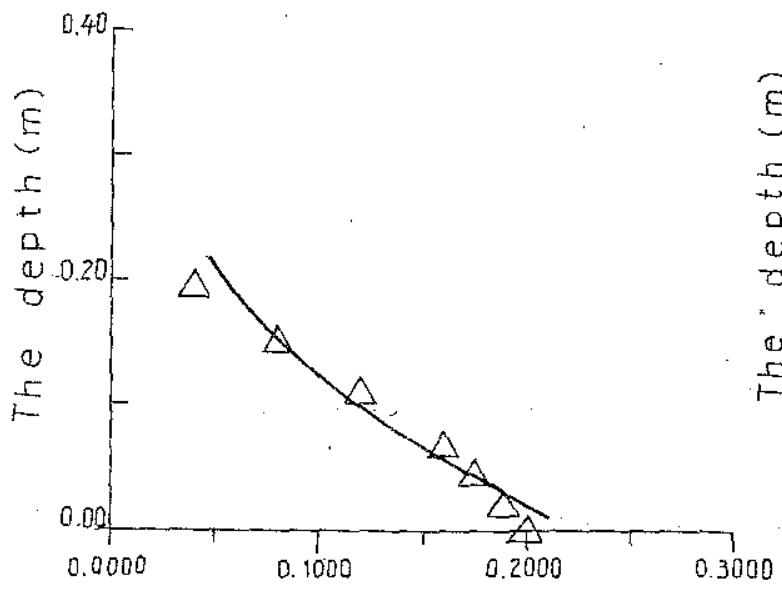

Fig. 1. Concentration at $x=1 \mathrm{~m}\left(\mathrm{~kg} / \mathrm{m}^{3}\right)$

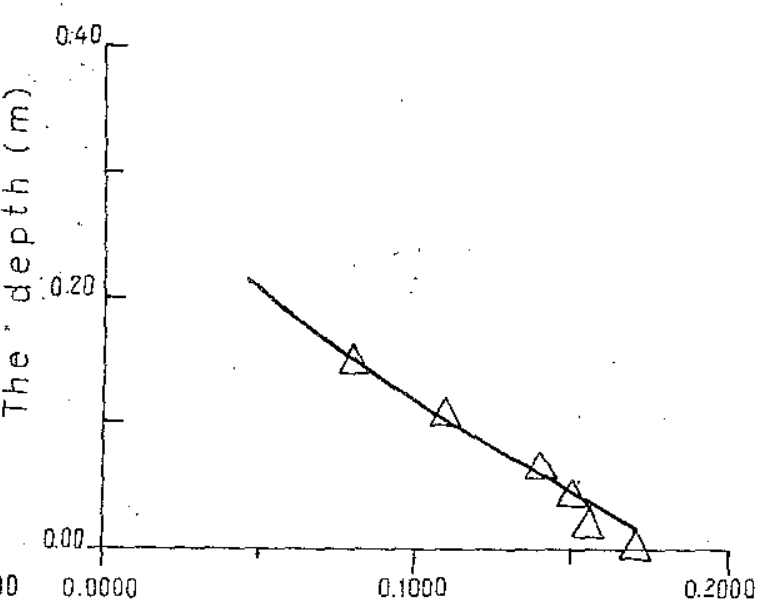

Fig. 2. Concentration at $x=2 \mathrm{~m}\left(\mathrm{~kg} / \mathrm{m}^{3}\right)$ 


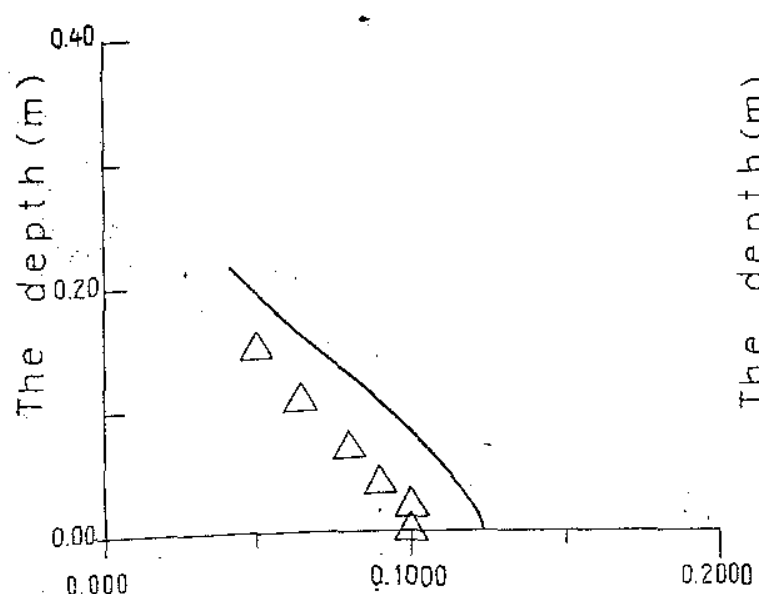

F:j. S. Concentration at $x=4.5 \mathrm{~m}\left(\mathrm{~kg} / \mathrm{m}^{3}\right)$

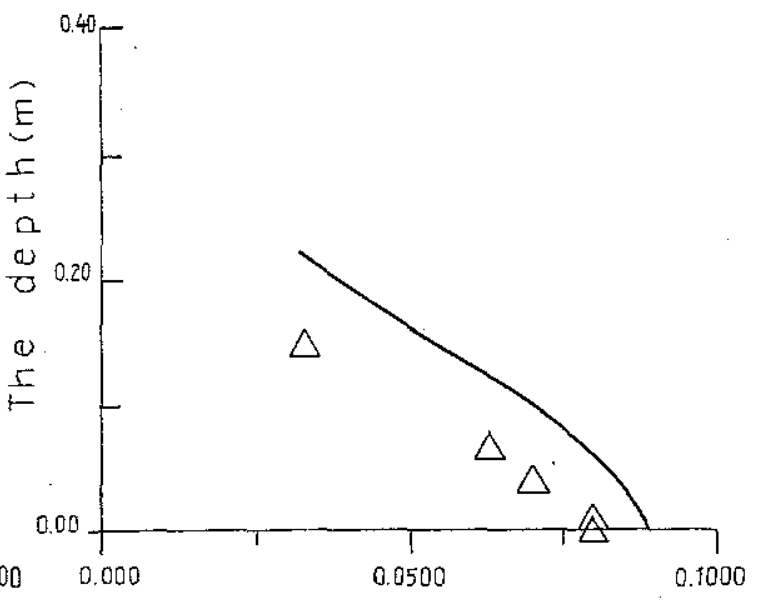

Fig. 4. Concentration at $x=8 \dot{\mathrm{m}}\left(\mathrm{kg} / \mathrm{m}^{3}\right)$

$\Delta$ flume data by Wang and Ribberink [5],

\section{REFERENCES}

1. A. T. Hjelmfelt and C. W. Lenau: Nonequilibrium transport of suspended sediment. Journal of the Hydraulics Division, Proc. ASCE, vol. 96, HY6, 1970.

2. H. E. Jobson and W. W. Sayre: Predicting concentration profile in open channels. Journal of the Hydraulics Division, Proc. ASCE, vol. 96, HY10, 1970.

3. B. A. O'Connor: Suspended sediment transport in the coastal zone. International Symposium on The Transport of Suspended Sediments And Its Mathematical Modelling. Florence (Italy),S eptember 2-5, 1991.

4. L. C. Van Rijn: Mathematical modeling of suspended sediment in nonuniform flows. Delft Hydraulics Communication No. 365, 1986.

5. L. C. Van Rijn: Mathematical modeling of morphological processes in the case of suspended sediment transport. Ph. D. Thesis. Delft Hydraulics Communication No: 382, 1987.

6. L. C. Van Rijn: Principles of fluid flow and surface waves in rivers, estuaries, seas and oceans. Aqua Publications, 1990, Netherlands.

7. L. C. Van Rijn: Hanbook on sediment transport by current and waves, Delft Hydraulics, Netherlands.

Rieceived May 4, 1999

\section{SƯ PHÂN BỐ NỒNG ĐỘ. BÙN CÁT LO LỬNG TRONG KÊNH CHIU ÂंNH HƯƠNG PHÙ SA}

Trong bài báo đã tìm lời giải số cho bài toán phân bổ nồng độ bùn cát lơ lửng trong kênh hở có mang phù sa trên cơ sở mô hình toán học "Profile model" do L. C. Van Rijn đề nghị. Mặc dù mô hình toán học tương đối đơn giản nhưng cũng đủ độ chính xác có thể áp dụng cho một số bài toán trong thực tế khi dòng chảy ớ trạng thái ởn định. Bài toán được giải bằng phương pháp sai phân hữu hạn. Sổ liệu dược sử dụng từ kết quả thí nghiệm trền máng cho trước. Kết quá tính toán chứng tờ răng sự phân bố nồng độ giảm nhanh dọc theo kênh và gradient nồng độ trở nên rất bé ơ tiết diện đủ xa thượng lưu. Ngoài ra đã xây dựng được bộ chương trình tính toán cho phép thể hiện kết quả tính toán bằng đồ thị. 